\title{
Dynamic participation processes for policy packaging in transport backcasting studies
}

\author{
Julio A. Soria-Lara, David Banister
}

\begin{abstract}
A B S T R A C T
Scenario analysis is particularly useful when major changes are required to reach climate change goals over a longer time period. Backcasting provides one approach to develop policy packages that together will help achieve these objectives, but one missing element has been the role that stakeholder engagement can play in the identification of suitable policy measures, in the packaging process, and in determining the suitability, the feasibility and the timescale involved. This paper develops a novel dynamic participatory process to address the policy-implementation gap through the engagement of practitioners, policy makers and researchers in a series of workshops that allow these issues to be discussed in an open deliberative process. The spatial context taken is the Andalusia region (Spain), where there is a clear policy desire to implement a sustainable transport strategy for 2050. The paper outlines the methodological process, the development of the policy pathways, the dialogue process, the refinement of the policy pathways, the final strategy, and it then reflects on the usefulness of stakeholder engagement in the policy formulation process.
\end{abstract}

\section{Introduction}

The backcasting approach is one type of scenario analysis particularly useful when the business-as-usual case is no longer appropriate, and significant changes in transport policy are required in order to reach climate goals (Banister et al., 2000; Hickman et al., 2011; Hickman and Banister, 2014; Höjer and Mattsson, 2000; Mattila and Antikainen, 2011; Niemeier et al., 2008; Olsson et al., 2015; Tuominen et al., 2014). It first establishes desirable endpoints in the longer term, and it then examines the policy pathways to reach those futures (Vergragt and Quist, 2011).

This paper focuses on the "policy packaging phase" of transport backcasting studies. The strong emerging consensus is that integrated policy measures -including smarter choices, green technologies, ecological driving, etc.- are all required to achieve desired transport futures (Hickman et al., 2012 p. 561). For this reason, the policy packaging phase firstly focuses on identifying a long list of policy measures. Those policies are then assessed in terms of their levels of implementation and effectiveness individually, before being clustered into mutually supporting policy packages. Then, the policy packages are combined to provide policy pathways to reach the desirable endpoints (futures targets) that have been set. They are finally assessed according to their suitability, political feasibility and timescale (Fig. 1).

The main question being addressed here is how the policy packaging phase can best engage stakeholders. Two-way interactions between researchers and stakeholders have been extensively used in the past (e.g. Delphi surveys, interviews, extensive discussions) (Hickman et al., 2009; Marchau and Van Der Heijden, 2003; Tuominen et al., 2014; Zimmermann et al., 2012). It is argued in this paper that a continuous process of stakeholder involvement is one means to bridge the implementation gap between research and effective action (Banister and Hickman, 2013).

A participatory approach for the policy packaging phase of transport backcasting studies has been developed through three interrelated steps: (i) A bottom-up process, in which practitioners and policymakers determine both the relevant policy packages and the pathways for implementation; (ii) A dynamic implementation of dialogue spaces, which evolves from generic and preliminary discussions to specific and focus-group views; (iii) A learning process, where participants can meet face-to-face, promoting transparency in mutual discussions, so that refinement of collective views can take place. The context of the transport sector in Andalusia (Spain) is used as a case study. The participants' views on the implementation of a set of policy packages to reach a pre-established Andalusian transport future by 2050 have 


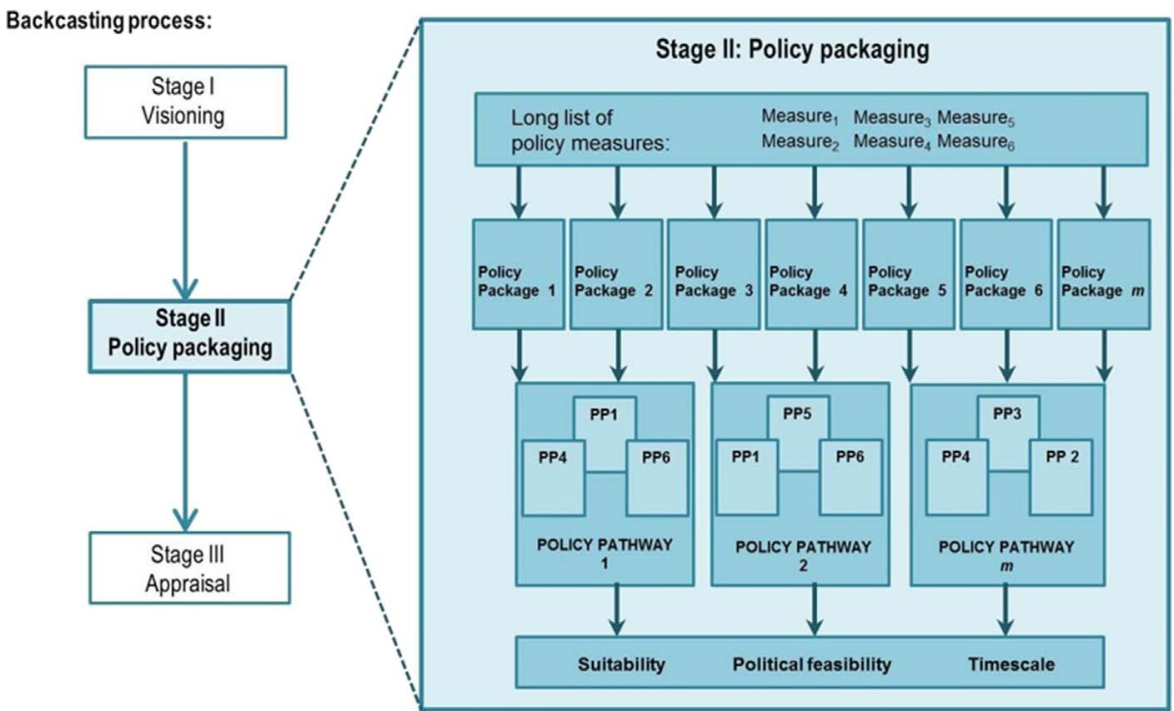

Fig. 1. Policy package scheme. Inspired by Hickman et al. (2012).

formed the basis for a final transport scenario. The "transport scenario" is defined here as the desired transport future (2050), together with the combination of policy packages that provide three individual policy pathways to reach the desired transport future: lower carbon emissions, technological innovation and urban compactness.

Section 2 outlines the theoretical framework, and the desired transport future for Andalusia. This transport future provides the basis for the participatory policy packaging phase, which is the main focus of this paper. Section 3 presents the research design, including a detailed description of the participatory approach. Section 4 shows the main results, while Section 5 closes the paper with some reflections and concluding remarks.

\section{Background and context}

\subsection{Participatory policy packaging in transport backcasting studies}

Although many transport backcasting studies only occasionally involve stakeholders (Ashina et al., 2012; Hickman and Banister, 2007; Markus and Jonsson, 2006; Mattila and Antikainen, 2011; Schade and Schade, 2005; Winyuchakrit et al., 2011), a growing number of studies emphasise the use of participatory methods during the policy packaging phase (Marchau and Van Der Heijden, 2003; Shiftan et al., 2003; Tuominen et al., 2014; Zimmermann et al., 2012).

The use of participatory workshops is one of the common methods used by different authors (Banister and Hickman, 2013; Hickman et al., 2011; Tuominen et al., 2014). For example Banister and
Hickman (2013) combined workshops and extensive discussions with colleagues in the context of Delhi (India). The results included the design of 8 policy packages (e.g. low emissions vehicles; alternative fuels) to reach three desirable transport futures by 2030. In a similar way, Hickman et al. (2011) compared several pathways to reach lower carbon emissions from London (U.K) and Delhi (India). Tuominen et al. (2014) also used participatory workshops to design policy packages in the context of Finland. The key dimensions to create those policy packages were: (i) Timing and preconditions for implementation; (ii) Timescale; (iii) Spatial scale; (iv) Interactions with other societal sectors. Marchau and Van Der Heijden (2003) combined workshops with conferences and interviews, incorporating visions from different stakeholders. They aimed at defining the scope of policy development in the context of possible Automated Vehicle Guidance developments.

Other participatory methods (e.g. surveys and/or interviews) have been also used. For example, Zimmermann et al., (2012) conducted a qualitative backcasting approach, designed to visualise a desirable electric mobility future in Germany, and to determine the measures to bridge the present and this desirable future. It was combined a Delphi process and interviews from 15 different stakeholders groups.

These studies mainly focused on two-way interactions between researchers and stakeholders. The present research goes further and explores the usefulness of open, interactive and learning dialogue spaces for the policy packaging phase of transport backcasting studies, where participants can actively interact with each other - this is a dynamic participation process.

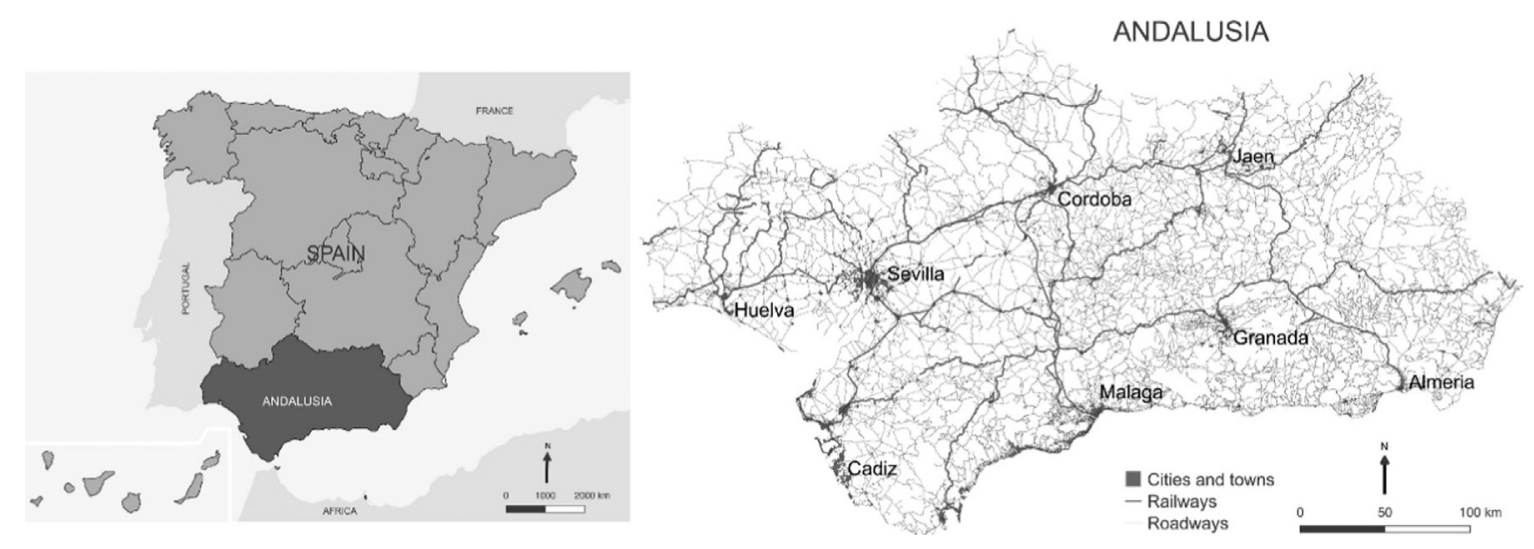

Fig. 2. Case study location. 


\subsection{The region of Andalusia: a desired transport future}

The region of Andalusia (Spain) has 8,402,305 inhabitants (Fig. 2). A new strategic plan is currently being discussed by the "Agencia Andaluza de la Energía" to meet climate change targets by 2050 (Agencia Andaluza de la Energía, 2014). It mainly aims at covering three main objectives: (i) Reaching $20 \%$ reduction in the use of primary energy; (ii) An increment of $20 \%$ in the percentage of renewable energy; (iii) A reduction of $\mathrm{CO}_{2}$ emissions of $60 \%$ by 2050 compared with domestic emissions in 1990 (in all sectors, including transport).

Given this context, a desired transport future of the Andalusian transport sector (2050) was created, exploring the preferences and the concerns from Andalusian society. To address this, a participatory process was conducted combining a Delphi analysis and semi-structured interviews from a wide range of stakeholders (Soria-Lara and Banister, 2017). In contrast to the business-as-usual projection (BAU), the results showed the desire of a radical transformation in both the Andalusian economic model and how people experience the transport sector (Table 1).

Table 1

Contrasting the BAU projection with the desired transport future in Andalusia. Source: Soria-Lara and Banister (2017)

\begin{tabular}{ll}
\hline BAU (by 2050) & Desired transport future (by 2050) \\
\hline - Tourism and agriculture sectors will & - Strong technological and industrial \\
dominate Andalusia GDP & sectors \\
- Car-oriented society & - Public transport-oriented society \\
- Low penetration of private electric & - Substitution of traditional fuels by \\
vehicles & electric and hybrid vehicles \\
- Increasing of distances to daily & $-\begin{array}{l}\text { Decreasing of distances to daily } \\
\text { destinations }\end{array}$ \\
$-\begin{array}{l}\text { Public transport as predominantions } \\
\text { mode at city level }\end{array}$ & Non-motorised and liveable cities \\
\hline
\end{tabular}

The storyline of the desired transport future provides the basis for the formulation of different policy pathways covered in this paper, which bridges the gap between the present and this future. Soria-Lara and Banister (2017) have presented the storyline as follows:

"This desirable transport future relies on a fundamental change in the economic model of Andalusia. The agricultural model would be more orientated towards the production of high-quality ecological products focusing on local consumption, reducing the distance of freight travel and facilitating home delivery of goods. Meanwhile, the existing coastal tourism is expected to decrease and to become re-orientated as a sustainable tourist model based on cultural tourism (e.g. historic monuments, town centres, etc.). This means a reduction of both air and car traffic.

Collective and public transport systems would provide the main motorised transport modes in Andalusia by 2050, with the preferred mode being the railway transport system (even for freight transport). The use of private vehicles would be strongly reduced, fostering car sharing initiatives between citizens. The implementation of zero and low emissions vehicles would be strongly promoted in both private and public transport modes (principally electric and hybrid vehicles), including the introduction of electric bikes.

There would be a preference for cities to be free of motorised vehicles, where the distances to daily destinations were shorter. In this sense, part of the existing car infrastructures would be used as socialization spaces for pedestrians; cycling and public transport infrastructures, including an increase in the number of intermodal facilities, as this would encourage a higher use of public transport modes".

This future image was obtained through a participatory process that combined two different methods: (i) Delphi methods; (ii) semistructured interviews. A total of 40 Andalusian stakeholders participated in the study. The Delphi method was intended to reach consensus between participants, and the semi-structured interviews

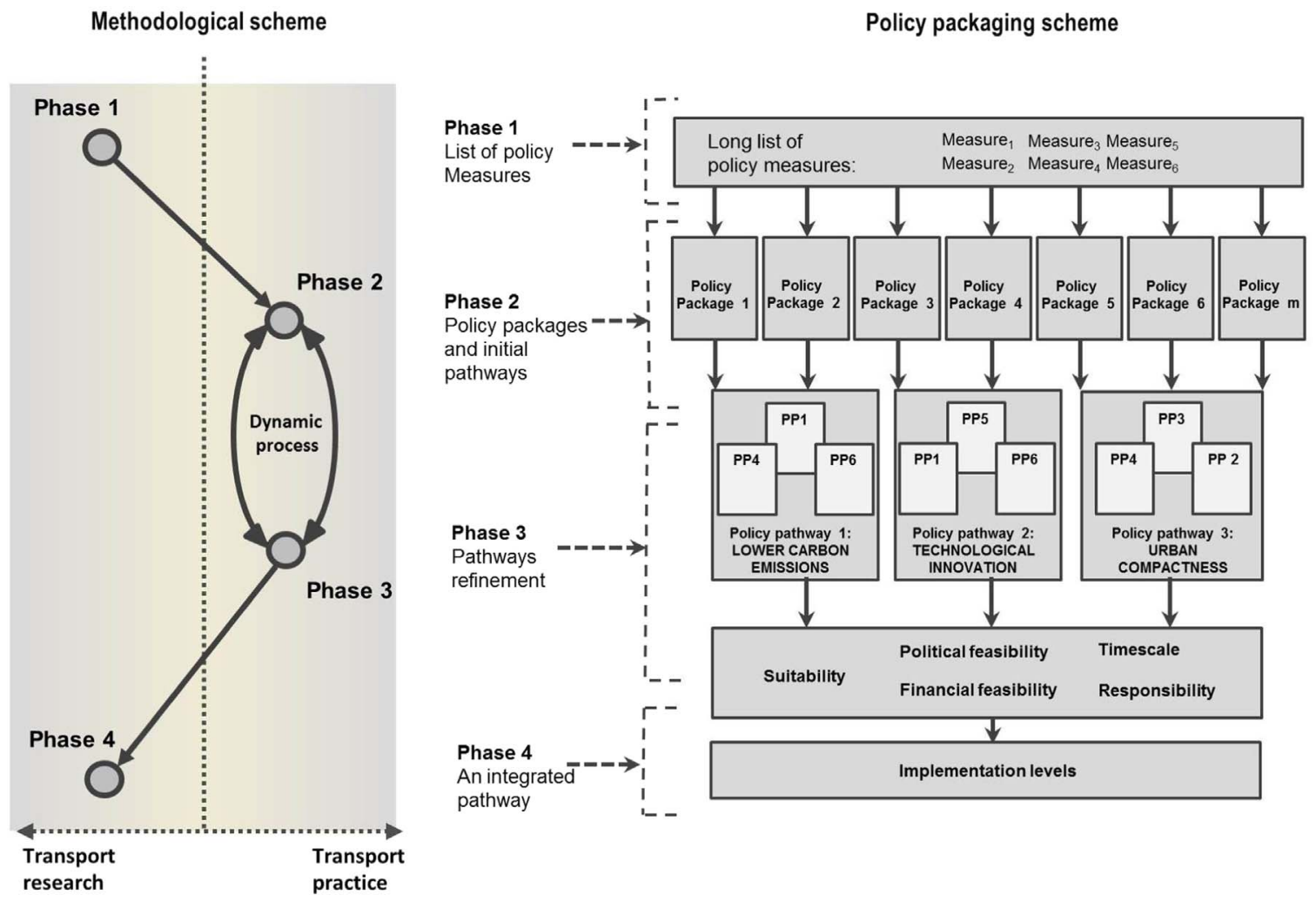

Fig. 3. Research method. Inspired by Hickman et al. (2012). 
represented a much more open participatory process. The interviewer had a series of general questions, as well as having some latitude to ask more detailed follow-up questions in response to what are seen as significant replies (Soria-Lara and Banister, 2017).

The present paper develops a set of policy packages and pathways for implementation to reach the desired transport future for Andalusia described above. To do that, a novel methodological approach has been developed, based on dynamic and learning dialogue spaces involving researchers, practitioners and policy-makers.

\section{The dynamic participation approach: research design}

The participatory process was structured into four sequential phases that interactively combines both: transport research and transport practice (Fig. 3): (i) Policy measures; (ii) Policy packages and initial pathways; (iii) Pathways refinement; (iv) An integrated pathway.

\subsection{Phase 1: policy measures}

The research team carried out a comprehensive review of the full range of policy measures. This review was based on academic articles and experiences from European transport practice. A total of 53 individual policy measures were selected as being relevant for the objectives of the pre-established future for Andalusia (Section 2.2). The practitioners and policy-makers were also encouraged to add further policy measures if necessary.

\subsection{Phase 2: policy packages and initial pathways}

Phase 2 was operationalised through a workshop where practitioners and policy-makers met face-to-face. The aim of the workshop was to: (i) cluster the list of 53 policy measures into different policy packages; (ii) define three initial policy pathways designed to reach the desired transport future for Andalusia. The themes of the three pathways were: (i) Lower carbon emissions; (ii) Technological innovation; (iii) Urban compactness. The choice of those three pathways is related to how Andalusian's stakeholders visualised the desired transport future for Andalusia, highlighting those three topics as desired pathways in the shorter, medium and longer term (Soria-Lara and Banister, 2017).

A total of 12 participants took part (Table 2). An experienced transport consultant took on the role of mediator, and the researchers mainly acted as observers. The duration of the workshop was flexible (approximately $3 \mathrm{~h} 30 \mathrm{~h}$ divided into two steps with a break).

The research team first detailed the pre-established transport future for Andalusia, focusing on the three possible policy pathways: (i) Lower carbon emissions; (ii) Technological innovation; (iii) Urban compact-

Table 2

Description of participants during Phase 2.

\begin{tabular}{ll}
\hline Professional groups & Number of participants and description \\
\hline Policy-makers & 3 from the regional government \\
& 3 from local governments \\
& 2 from the technological sector \\
& 2 transport planners \\
& 1 sociologists \\
& 1 urban planner \\
\end{tabular}

ness. Then, participants were provided with the list of 53 individual policies, and were asked to classify such policies into different policy packages. Consensus was sought to identify the criterion that would help to classify the list of policy measures into policy packages. Each policy package should be based on: (i) A set of individual measures with a similar nature (e.g. technological, economic, lifestyle etc.); (ii) Measures that are likely to work well together; (iii) Measures that might create positive synergies. Participants were also encouraged to add additional policy measures.

Participants were then asked to indicate the suitability and political feasibility of each policy package for each of the three individual pathways. The levels of consensus between participants were meant to distinguish between three suitability and political feasibility levels: (i) Low; (ii) Medium; (iv) High. The results provided the three initial pathways.

\subsection{Phase 3: pathways refinement}

In this Phase three focus-group workshops were organised, focusing respectively on the three initial pathways developed during the previous phase. A total of 12 participants took part in each focusgroup workshop (Table 3 ). Some participants $(3-5)$ provided continuity between the Phases 2 and 3. The duration of each focus-group workshop was flexible, dividing each workshop into three steps with two breaks (Fig. 4).

Researchers were firstly showed the desired transport future for Andalusia, and this was supplemented by one of the three initial pathways: lower carbon emissions (1st workshop), technological innovation (2nd workshop) and urban compactness (3rd workshop). Participants had to distinguish between five suitability levels from each policy package: (i) Very low; (ii) Low; (iii) Medium; (iv) High; (v) Very high. Suitability showed how each policy package fitted into a specific policy pathway. The increased degree of separation 3-5 options) between Phases 2 and 3 resulted from the need for higher sensitivity, and it was thought that there was more experience from the participants with the thinking behind the policy packages.

Participants then discussed the political and financial feasibility of the policy packages. Political feasibility referred to the possibility that policy measures would be implemented without paying attention to financial issues, and focusing on aspects such as: direct or indirect implementation from institutions, ease of communication, social acceptability, etc. Financial feasibility referred to the possibility that policy implementation would be influenced according to their costs. Participants again had to distinguish between five feasibility levels: (i) Very low; (ii) Low; (iii) Medium; (iv) High; (v) Very high.

Participants were thirdly asked to reflect on the timescale and responsibility for policy implementation. With regard to the timescale, participants had to select between three different temporal horizons for each policy measure: (i) Shorter-term (2025); (ii) Mid-term (2035); and (iii) Longer term (2050). Concerning the responsibility for policy implementation, participants had to select between: (i) Regional institutions; (ii) Local institutions; (iii) Citizens; and (iv) Private sector.

\subsection{Phase 4: an integrated policy pathway}

The final stage required the presentation of an integrated policy pathway that focused on identifying several levels of implementation for the range of policy packages, based on: (i) the combined suitability of policy packages for the three individual pathways; and (ii) the combined political and financial feasibility of policy packages for the three individual pathways. 
Table 3

Description of participants during Phase 3.

\begin{tabular}{|c|c|c|c|}
\hline \multirow[t]{2}{*}{ Professional groups } & \multicolumn{3}{|c|}{ Number of participants and description } \\
\hline & $\begin{array}{l}1^{\text {st }} \text { Focus-group workshop: } \\
\text { Lower Carbon Emissions }\end{array}$ & $\begin{array}{c}2^{\text {nd }} \text { Focus-group workshop: } \\
\text { Technological innovation }\end{array}$ & $\begin{array}{l}3^{\text {rd }} \text { Focus-group workshop: } \\
\text { Urban compactness }\end{array}$ \\
\hline Policy-makers & $\begin{array}{l}3 \text { from the regional government } \\
3 \text { from local government }\end{array}$ & $\begin{array}{l}3 \text { from the regional government } \\
3 \text { from local government }\end{array}$ & $\begin{array}{l}3 \text { from the regional government } \\
3 \text { from local government }\end{array}$ \\
\hline Consultants & $\begin{array}{l}2 \text { geographers } \\
2 \text { sociologists } \\
2 \text { environmentalists }\end{array}$ & $\begin{array}{l}2 \text { car manufacturers } \\
2 \text { bike manufacturers } \\
2 \text { train manufacturers }\end{array}$ & $\begin{array}{l}3 \text { architects } \\
2 \text { transport planners } \\
1 \text { traffic engineer }\end{array}$ \\
\hline
\end{tabular}

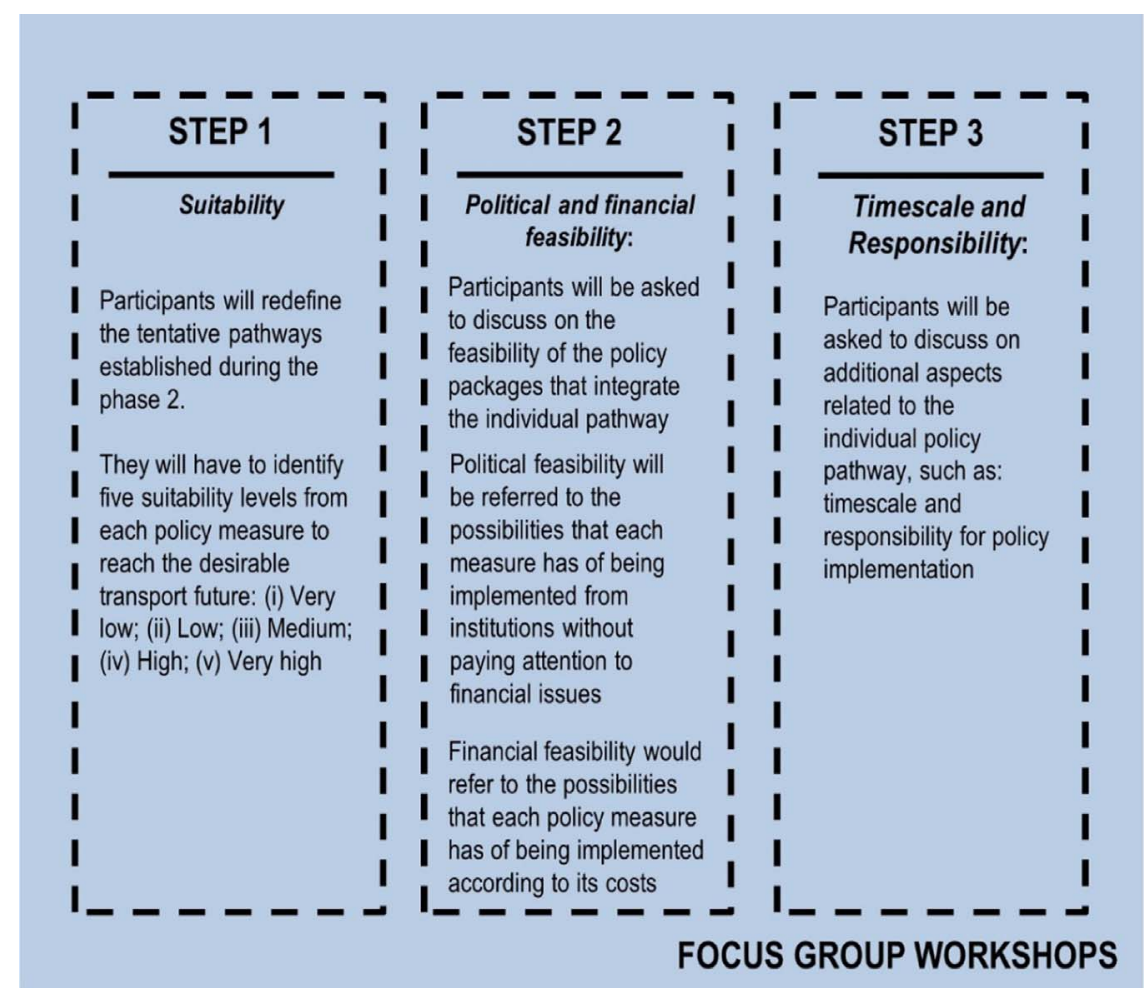

Fig. 4. Setup of focus group workshops.

\section{Results}

\subsection{Definition of policy packages}

The 53 policy measures were clustered into different policy packages (PPs), and this was operationalised through a workshop where participants met face-to-face (Phase 2). PPs were, therefore, created by combining a set of individual measures that are likely to work well together, concentrating on those that might create positive synergies. A total of ten PPs were developed. Participants decided both the theme of each PP and the constituent set of measures (Table 4).
Two main discussions appeared. The first focused on whether the policies related to the freight transport sector should be combined in a specific PP, rather than being distributed among the rest of PPs. The final decision was to create a specific PP on freight transport due to its relevance for Andalusia's emissions. The second discussion focused on whether the policies related to non-motorised transport modes should be added to PP6 liveable cities. Participants finally signalled that the policies related to non-motorised modes should be part of a separate PP, while PP6 liveable cities should be exclusively focused on land use policies. 
Table 4

Description of policy packages (PPs).

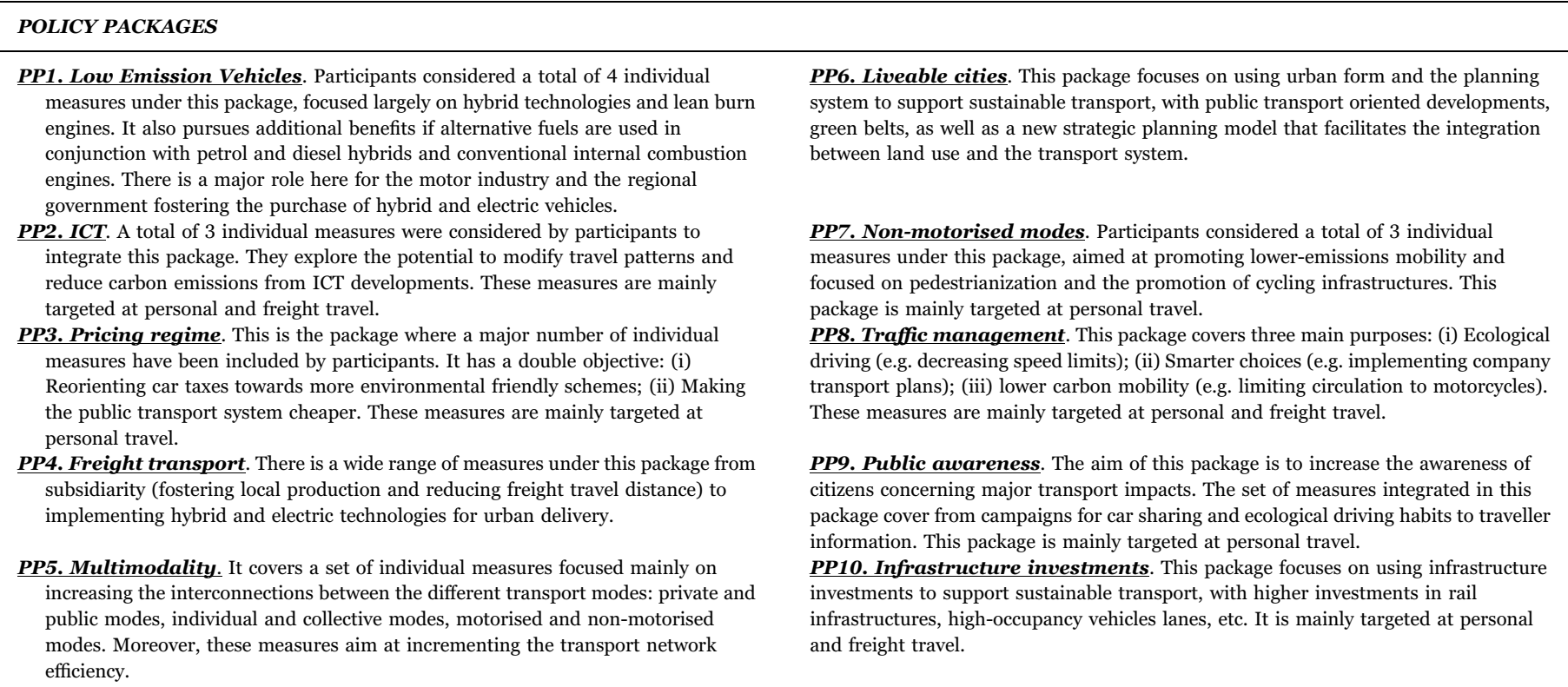

\subsection{Policy pathway 1: lower carbon emissions}

The development of this pathway followed a dynamic process of refinement, operationalised through 2 different workshops. The first workshop was generic and focused on defining an initial pathway (Phase 2). The second workshop was based on focus-group participants, and it was much more specialised (Phase 3).

The initial stages of this focus-group workshop (Phase 3) were not really productive due to the different language approaches used between participants. While policy-makers notably focused their discourse on economic issues related to policy packages (e.g. economic sustainability; capacity to make profit, etc.), the rest of participants discussed more from the social benefits of policy packages. This initially generated controversial views and non-compatible discourses. Then, the mediator stopped the discussion, and facilitated a specific discussion-framework where the discourse from both sides were intrinsically recognised and integrated. The mediator encouraged participants to separately discuss the convenience of each policy package from economic, environmental, and societal viewpoints. This meant that policy-makers should avoid the almost exclusive focus on economic issues and appreciate other perspectives. The same rules were imposed on the other groups. Together, this provided participants with a new understanding, orientated towards creating a common language to facilitate agreement. At the end of the focus-group workshop, three implementation levels of PPs were finally identified (Table 5). The highest priority was given to PP5 Multi-modality and PP10 Infrastructure investments, while an intermediate priority was given to the following PPs: PP7 Non-motorised modes, PP1 Low emission vehicles and PP4 Freight transport. The rest of PPs were signalled as low-priority.

The refinement process demonstrated the disagreement about which PPs were more suitable for this pathway, and it triggered an interesting learning process that adjusted initial differences between participants. While participants from the first workshop (Phase 2) indicated that a combination of a wide spectrum of PPs was needed, this thinking was not followed by participants from the second workshop (Phase 3 ). In this respect, the three people (2 policy-makers and 1 sociologist) who had participated during the first (generic) workshop supported (during the second workshop) the need of a wide spectrum of PPs for this policy pathway. However, the rest of participants (who had not participated during the first workshop) strongly argued on the convenience of reducing the number of PPs as being most suitable. Arguments on the need to be specific and reliable during the design of policy pathways convinced the three participants from the first workshop to change their initial views. It was collectively concluded that "reducing the number of PPs with high suitability was needed to make the pathway more reliable and feasible". Accordingly, the number of PPs highly suitable was reduced from the initial seven to five (Table 5). This was inspired by the belief that "the most effective way to achieve a lower carbon Andalusian society should be based on an effective modal shift from conventional transport modes to lower emissions modes". It also highlighted the final inclusion of PP4 Freight transport as highly suitable after the first workshop, arguing that " $a$ transition towards rail freight transport could drastically reduce the carbon emissions in Andalusia".

Participants also signalled PP7 Non-motorised modes and PP5 Multi-modality as the most politically feasible due to "no big interventions were needed at the city level". However, the financial feasibility was seen as an important shortcoming of the selected PPs. The most suitable timescale was the mid-term (2035) and longer-term (2050). Both local and regional institutions were seen to have main responsibility for the implementation of PPs, and the private sector was also seen to be essential, as in the case of PP1 Low emission vehicles and PP4 Freight transport.

It is worth mentioning that no power dynamics between participants were highlighted. The mediator had a central position ensuring that no participant/group took a dominant role in the discussion, and participants respected that independence. 
Table 5

Policy pathway 1: lower carbon emissions.

\begin{tabular}{|c|c|c|c|c|c|}
\hline \multirow[t]{2}{*}{ Policy package } & \multirow[t]{2}{*}{ Suitability } & \multicolumn{2}{|c|}{ Feasibility } & \multirow[t]{2}{*}{ Timescale } & \multirow[t]{2}{*}{ Responsibility } \\
\hline & & Political & Financial & & \\
\hline PP5. Multi-modality & Very high & High & Medium & Mid-term & Regional and local institutions \\
\hline $\begin{array}{l}\text { PP10. Infrastructure } \\
\text { investments }\end{array}$ & Very high & Medium & Low & Longer-term & Regional and local institutions \\
\hline PP7. Non-motorised modes & High & High & Medium & Mid-term & Local institutions \\
\hline PP1. Low emission vehicles & High & Medium & Low & Mid-term & $\begin{array}{l}\text { Regional, local institutions and } \\
\text { private sector }\end{array}$ \\
\hline PP4. Freight transport & High & Medium & Low & Longer-term & $\begin{array}{l}\text { Regional institutions and private } \\
\text { sector }\end{array}$ \\
\hline PP8. Traffic management & Medium & High & High & Shorter-term & Regional and local institutions \\
\hline PP3. Pricing regime & Medium & High & Very high & Shorter-term & Regional and local institutions \\
\hline PP6. Liveable cities & Medium & Medium & Medium & Mid-term & Local institutions \\
\hline PP9. Public awareness & Medium & High & Medium & Shorter-term & $\begin{array}{l}\text { Regional, local institutions and } \\
\text { citizens }\end{array}$ \\
\hline PP2. ICT & Very low & Low & Medium & Mid-Term & Private sector and citizens \\
\hline
\end{tabular}

Initial pathway

( $1^{\text {st }}$ Workshop)

1. A total of 7 PPs were signalled as highly suitable: (i) $P P 1$ Low emission vehicles; (ii) PP3 Pricing regime; (iii) PP5 Multi-modality; (iv) PP7 Non-motorised modes; (v) PP8 Traffic management; (vi) PP9 Public awareness; (vii) PP10 Infrastructure investments.

2. PP1 low emissions vehicles and PP3 pricing regime as the packages with the lowest political feasibility

3. High priority to those PPs low cost and with high impact on personal travel behaviour

4. High importance to coordinate local and regional institutions
The process of refinement:

Final pathway

( $2^{\text {nd }}$ Workshop)

1. A total of 5 PPs were signalled as highly suitable: (i) PP5 Multi-modality; (ii) PP10 Infrastructure; (iii) PP7 Non-motorised modes, (iv) PP1 Low emission vehicles; (iv) PP4 Freight transport

2. PP5 multi-modality and PP7 non-motorised modes as the packages with the highest political feasibility

3. PP10 Infrastructures investments, PP1 Low emission vehicles and PP4 Freight transport as the packages with the lowest financial feasibility

4. The timescale of PPs highly suitable was the midterm and longer-term

5. Both regional and local institutions were considered key to implement this policy pathway

\section{Changes-Refinement}

1. A reduction in the number of PPs highly suitable was recommended according to criteria of feasibility and reliability

2. The inclusion of PP4 freight transport as highly suitable was strongly recommended during the focus-group workshop

3. PP3 pricing regime, PP8 traffic management and PP9 public awareness were not considered highly suitable during the focus-group workshop

4. It was emphasised that this pathway would take a major effort from the motor manufacturers, responding to mandatory emissions standards, which in turn would require new EU and Andalusia legislation.

\subsection{Policy pathway 2: technological innovation}

The development of this pathway also followed a dynamic process of refinement, operationalised through the 2 workshops. The first was more generic (Phase 2). The second was much more specialised (Phase 3 ).

Two different kinds of languages were identified during the dynamic participatory process in the discussions of policy pathways. The first focused on technological issues and business models, and it was associated with participants who came from the technological sectors (mainly car, bike and train manufacturers). The second and more holistic perspective came from the rest of participants (policymakers and practitioners from several social sciences fields). These language profiles were not problematic during the first (generic) workshop, as the number of participants from the technological sector was small. However, more problems appeared to differentiate between languages during the second workshop, where the numbers from the technological sector were higher. To address that, the mediator encouraged participants to discuss on the convenience of each policy package at two overlapping levels. Firstly, participants discussed on technological implications of each policy package. Secondly, participants discussed on the role of each policy package on lifestyle, social preferences, etc. In this way, the discussion ranged from a more specific and technological discussion to a more general and holistic vision of the policy pathway. This also facilitated the creation of a common language between participants.

Finally, three implementation levels for PPs were identified for this pathway (Table 6). The highest priority was given to two PPs: PP1 Low emission vehicles and PP2 ICT. A second level of priority was given to PP4 Freight transport and PP8 Traffic management. The rest of PPs were signalled as low-priority.

While three PPs were indicated as being highly suitable for this pathway during the first workshop (PP1 Low emission vehicles; PP2 ICT; PP5 Multi-modality), focus-group participants concluded that PP5 Multi-modality was not so relevant, even "considering that technological innovations on collective transport modes would be higher in a context of excellent multi-modality". This was a consequence of the learning process implemented during the dynamic participatory process. Although, some participants (2 policy-makers and 1 train manufacturer) from first workshop explained why PP5 Multimodality was highly suitable for them, the rest of participants argued extensively and convincingly that PP5 had not a technological component itself. This reasoning facilitated the unanimous view that PP5 Multimodality should be removed as a high-priority PP. Moreover, focus-group participants agreed to indicate that both PP4 Freight transport and PP8 Traffic management should be recognised as highly suitable in the context of technological innovation, as there were a large number of technological innovations related to home delivery (e.g. drones or/and automated vehicles).

With the exception of PP4 Freight transport, it was concluded that the most suitable PPs were also highly feasible at the political level. However, only PP8 traffic management was considered highly feasible at the financial level. A recurrent theme in the conversation noted how the vehicles stock had increased recently, and the difficulties about improving their technological standards in the shorter-term. Participants also agreed that "there were important financial barriers from Andalusian local institutions to facilitate the implementation of electric and hybrid modes".

Regarding timescale and the implementation potential, PP1 Low emission vehicles and PP2 ICT were considered mid-term packages, while PP4 Freight transport was seen as a long-term package. Participants also highlighted the importance of the public sector for increasing the penetration of the technological innovation in the 
Table 6

Policy pathway 2: technological innovation.

\begin{tabular}{|c|c|c|c|c|c|}
\hline \multirow[t]{2}{*}{ Policy package } & \multirow[t]{2}{*}{ Suitability } & \multicolumn{2}{|c|}{ Feasibility } & \multirow[t]{2}{*}{ Timescale } & \multirow[t]{2}{*}{ Responsibility } \\
\hline & & Political & Financial & & \\
\hline PP1. Low emission vehicles & Very high & High & Low & Mid-term & $\begin{array}{l}\text { Regional, local institutions and } \\
\text { private sector }\end{array}$ \\
\hline PP2. ICT & Very high & High & Medium & Mid-Term & $\begin{array}{l}\text { Regional, local institutions, } \\
\text { private sector }\end{array}$ \\
\hline PP4. Freight transport & High & Low & Low & Longer-term & $\begin{array}{l}\text { Regional institutions and private } \\
\text { sector }\end{array}$ \\
\hline PP8. Traffic management & High & High & High & Shorter-term & Regional and local institutions \\
\hline PP3. Pricing regime & Medium & High & Very high & Shorter-term & Regional and local institutions \\
\hline PP5. Multi-modality & Medium & Medium & Medium & Longer-term & Regional and local institutions \\
\hline PP9. Public awareness & Medium & High & Medium & Shorter-term & $\begin{array}{l}\text { Regional, local institutions and } \\
\text { citizens }\end{array}$ \\
\hline PP10. Infrastructure investments & Medium & Low & Low & Longer-term & Regional and local institutions \\
\hline PP6. Liveable cities & Low & Medium & High & Mid-term & Local institutions \\
\hline PP7. Non-motorised modes & Low & High & High & Mid-term & Local institutions \\
\hline \multicolumn{2}{|c|}{$\begin{array}{l}\text { Initial pathway } \\
\left(1^{\text {st }} \text { Workshop }\right)\end{array}$} & \multicolumn{2}{|c|}{$\begin{array}{r}\text { Final pathway } \\
\left(2^{\text {nd }} \text { Workshop }\right)\end{array}$} & \multicolumn{2}{|c|}{ Changes-Refinement } \\
\hline \multicolumn{2}{|c|}{$\begin{array}{l}\text { 1. A total of } 3 \text { PPs were signalled as highly suitable: (i) PP1 Low } \\
\text { emission vehicles; (ii) PP2 ICT; (iii) PP5 Multi-modality. } \\
\text { 2. PP2 ICT was considered crucial for this pathway } \\
\text { 3. PP5 multi-modality was considered very important, as } \\
\text { technological innovations can have a higher impact on a more } \\
\text { efficient transport network } \\
\text { 4. Subsidies as a tool to facilitate the penetration of technological } \\
\text { innovations }\end{array}$} & $\begin{array}{l}\text { 1. A total } \\
\text { suitable: } \\
\text { PP2 ICT } \\
\text { Traffic r } \\
\text { 2. PP1 low } \\
\text { consider } \\
\text { 3. The tin } \\
\text { between } \\
\text { 4. Both re } \\
\text { consider } \\
\text { pathway }\end{array}$ & $\begin{array}{l}\text { re signalled as highly } \\
\text { gmission vehicles; (ii) } \\
\text { ght transport; (iv) PP8 } \\
\text { icles and PP2 ICT were } \\
\text { this pathway } \\
\text { s highly suitable was } \\
\text { longer-term } \\
\text { ocal institutions were } \\
\text { ement this policy }\end{array}$ & \multicolumn{2}{|c|}{$\begin{array}{l}\text { 1. An increase in the number of PPs highly suitable was } \\
\text { recommended according to criteria of feasibility and } \\
\text { reliability } \\
\text { 2. The exclusion of PP5 Multi-modality as highly suitable } \\
\text { was strongly advised during the focus-group workshop } \\
\text { 3. The inclusion of PP4 Freight transport and PP8 Traffic } \\
\text { management as highly suitable was strongly advised } \\
\text { during the focus-group workshop } \\
\text { 4. It was highlighted that the effects of the financial crisis } \\
\text { in Andalusia was an important barrier to overcome, } \\
\text { fundamentally in those aspects related to car } \\
\text { manufacturing and implementation of new } \\
\text { technologies in massive transport modes }\end{array}$} \\
\hline
\end{tabular}

Andalusian transport sector (e.g. subsidies).

The power dynamics between participants triggered some problems for the mediator during the implementation of the dynamic participatory process. This was especially relevant during the focus-group workshop. Participants from the technological sector (2 car manufacturers, 2 bike manufacturers, and 2 train manufacturers) tended to spend more time than others making their interventions, and they did not really appreciate the views from the rest of participants. Recurrent efforts from the mediator were made to address this particular situation. First, the mediator stopped the discussion to allot equivalent speaking time to each party. Second, the mediator specifically gave an opportunity to those participants that felt less safe to talk.

\subsection{Policy pathway 3: urban compactness}

The development of this pathway also followed a dynamic process of refinement, with the first workshop being more generic (Phase 2) and the second more detailed (Phase 3). The dynamic of language differences between participants was not a relevant issues here. There was no problem during the workshops in this respect, and all participants seemed to feel comfortable hearing and understanding views from each other. Three implementation levels of PPs were identified (Table 7). The highest priority was given to four PPs: PP5 Multi-modality, PP6 Liveable cities, PP7 Non-motorised modes and PP8 Traffic management. An intermediate level of priority was given to PP10 Infrastructure investments. The rest of PPs were considered less relevant.

A description of the learning process showed that there was consensus between participants from the first and second workshop, considering that PP6 Liveable cities, PP7 Non-motorised modes and PP10 Infrastructure investments were highly suitable for this pathway. However, focus-group participants indicated that only these three packages seemed to be insufficient. Accordingly, they also signalled
PP8 Traffic management and PP5 Multi-modality as being also highly suitable. In both workshops, participants highlighted that a large effort should be made to change the current Andalusian policies to achieve higher levels of urban compactness, since limited attention has been traditionally paid to the impact of urbanisation processes on transport.

A medium level of political feasibility was assigned to PP6 Liveable cities and PP10 infrastructure investments, while participants indicated as highly feasible the rest of suitable PPs. However, the financial feasibility of PP10 Infrastructure investments was indicated as low. Participants considered "very hard to achieve funding from local and regional institutions for new transport infrastructures, since over the last years too budget was spent in transport infrastructure such as regional highways, international airports and high speed rail. So, the social acceptability of this PP could became extremely low".

Regarding timescale and the implementation potential, with the exception of PP10 Infrastructure investments, signalled as a longerterm package, the rest of PPs were considered shorter-term packages. Participants highlighted "the urgency of implementing packages such as PP5 multi-modality and PP7 non-motorised modes to reach a higher urban compactness". Finally, participants declared that both regional and local institutions should be responsible for the implementation of this pathway.

The power dynamics between participants were the more evident during the implementation of the participatory process in this policy pathway, and this was really significant during the focus-group workshop. Architects and transport planners tended to establish a bidirectional discussion between them, and this extended the duration of the workshop by almost $1 \mathrm{~h}$. The mediator made a big effort to give a voice to the rest of participants. However, this intervention was not effective on several occasions during the workshop. Although the mediator stopped the discussion several times to allot equivalent speaking times, this did not work well for this policy pathway. 
Table 7

Policy pathway 3: urban compactness.

\begin{tabular}{|c|c|c|c|c|c|}
\hline \multirow[t]{2}{*}{ Policy package } & \multirow[t]{2}{*}{ Suitability } & \multicolumn{2}{|c|}{ Feasibility } & \multirow[t]{2}{*}{ Timescale } & \multirow[t]{2}{*}{ Responsibility } \\
\hline & & Political & Financial & & \\
\hline PP5. Multi-modality & Very high & High & Medium & $\begin{array}{l}\text { Shorter-term, Mid- } \\
\text { term }\end{array}$ & Regional and local institutions \\
\hline PP6. Liveable cities & Very high & Medium & Medium & Mid-term & Local institutions \\
\hline PP7. Non-motorised modes & Very high & High & Medium & Mid-term & Local institutions \\
\hline PP8. Traffic management & Very high & High & High & Shorter-term & Regional and local institutions \\
\hline $\begin{array}{l}\text { PP10. Infrastructure } \\
\text { investments }\end{array}$ & High & Medium & Low & Longer-term & Regional and local institutions \\
\hline PP3. Pricing regime & Medium & High & Very high & Shorter-term & Regional and local institutions \\
\hline PP4. Freight transport & Medium & Medium & Low & Longer-term & $\begin{array}{l}\text { Regional institutions and private } \\
\text { sector }\end{array}$ \\
\hline PP9. Public awareness & Medium & High & Medium & Shorter-term & $\begin{array}{l}\text { Regional, local institutions and } \\
\text { citizens }\end{array}$ \\
\hline PP1. Low emission vehicles & Low & Low & Low & Mid-term & $\begin{array}{l}\text { Regional, local institutions and } \\
\text { private sector }\end{array}$ \\
\hline PP2. ICT & Very low & High & Medium & Mid-Term & $\begin{array}{l}\text { Regional, local institutions, } \\
\text { private sector and citizens }\end{array}$ \\
\hline \multicolumn{2}{|c|}{$\begin{array}{l}\text { Initial pathway } \\
\text { (1 }{ }^{\text {st }} \text { Workshop) }\end{array}$} & \multicolumn{2}{|c|}{ The process of refinement: } & \multicolumn{2}{|c|}{ Changes-Refinement } \\
\hline \multicolumn{2}{|c|}{$\begin{array}{l}\text { 1. A total of } 3 \text { PPs were signalled as highly suitable: (i) PP6 } \\
\text { Liveable cities; (ii) PP7 Non-motorised modes; (iii) } \\
\text { PP10 Infrastructure investments } \\
\text { 2. PP6 Liveable cities was considered crucial for this } \\
\text { pathway } \\
\text { 3. It was highlighted the limited attention paid in } \\
\text { Andalusia to the effects on urbanisation processes } \\
\text { on the transport sector }\end{array}$} & \multicolumn{2}{|c|}{$\begin{array}{l}\text { 1. A total of } 5 \text { PPs were signalled as highly suitable:(i) PP6 } \\
\text { Liveable cities; (ii) PP7 Non-motorised modes; (iii) } \\
\text { PP10 Infrastructure investments; (iv) PP8 Traffic } \\
\text { management; (v) PP5 Multi-modality } \\
\text { 2. PP6 Liveable cities and PP5 Multi-modality were } \\
\text { considered crucial } \\
\text { 3. The timescale of PPs highly suitable was between mid- } \\
\text { term and longer-term } \\
\text { 4. Both regional and local institutions were considered key } \\
\text { to implement this policy pathway }\end{array}$} & \multicolumn{2}{|c|}{$\begin{array}{l}\text { 1. An increase in the number of PPs highly suitable was } \\
\text { recommended according to criteria of feasibility and } \\
\text { reliability } \\
\text { 2. The inclusion of PP5 multi-modality and PP8 Traffic } \\
\text { management as highly suitable was strongly advised } \\
\text { during the focus-group workshop }\end{array}$} \\
\hline
\end{tabular}

\subsection{An integrated policy pathway}

From the three individual pathways established, the research team identified different levels of implementation for PPs (Phase 4). This was based on criteria of suitability, political and financial feasibility.

Regarding PPs' suitability, three different implementation levels were identified (Fig. 5). First, PP5 Multi-modality was seen as the most important PP for all three pathways studies. Second, a total of six PPs were identified within a second level of implementation. They were PP1 Low emission vehicles, PP4 Freight transport, PP6 Liveable cities, PP7 Non-motorised modes, PP8 Traffic management and PP10 Infrastructure investments. The remaining PPs formed a third implementation level with a medium suitability for the three pathways studied.

Concerning the political feasibility of PPs, two different implementation levels were recognised (Fig. 5). First, a total of six PPs were identified as the most politically feasible for the three pathways. They were PP2 ICT, PP3 Pricing regime, PP5 Multi-modality, PP7 Nonmotorised modes, PP8 Traffic management and PP9 Public aware- ness. Local and regional institutions were indicated as having the main responsibility for the implementation of those PPs. A second level of implementation would be integrated by PP1 Low emission vehicles, PP2 Freight transport, PP6 Liveable cities and PP9 Infrastructures investments. In voice of the participants, "the political feasibility of PPs such as PP1 Low emission vehicles and PP2 freight transport was lower than others due to the dependency of external factors to Andalusia (e.g. global market)". The low social acceptability of transport mega-projects in Andalusia due to financial crisis impedes the perception of a high political feasibility of PP6 Liveable cities and PP9 Infrastructure investments.

Finally, four different levels of implementation were identified that related to the financial feasibility of PPs. The highest financial feasibility was signalled for PP3 Pricing regime and PP6 Liveable cities, while the lowest financial feasibility was signalled for PP1 Low emission vehicles, PP4 Freight transport and PP10 Infrastructure investments. The rest of PPs were integrated into two intermediate levels of financial feasibility (Fig. 5). 


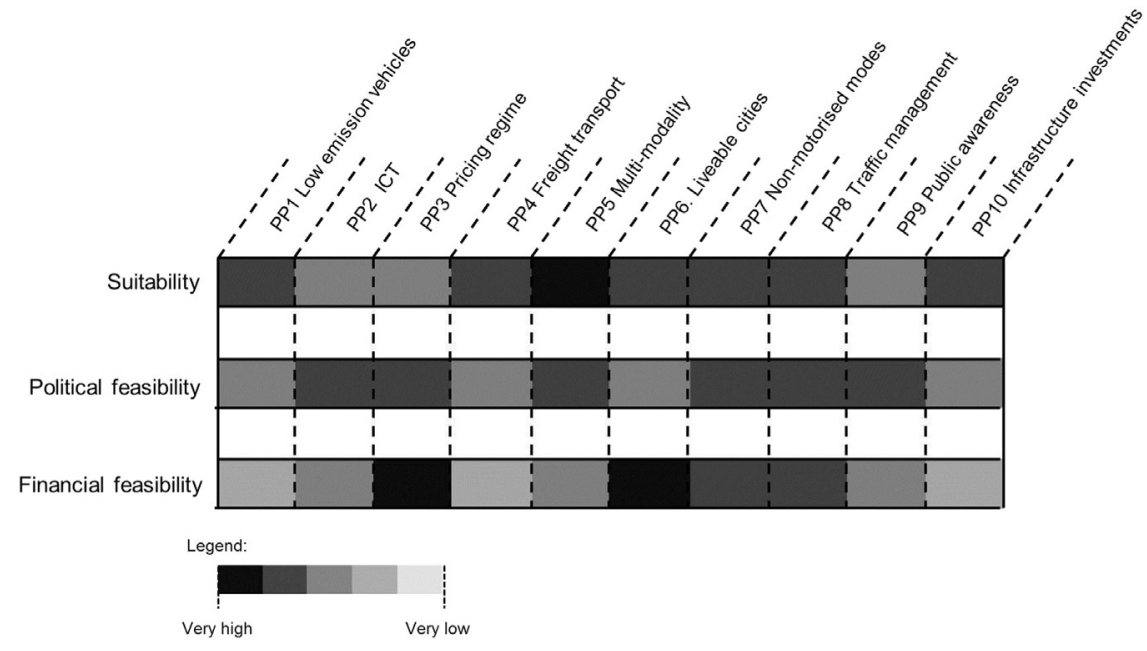

Fig. 5. Implementation levels and feasibility for the different PPs.

\section{Conclusions and discussion}

This paper has developed and tested a novel participatory approach applied to the policy packaging phase of transport backcasting studies. It has focused on dynamic dialogue spaces that involved researchers (as observers), practitioners and policy-makers. The Andalusian transport sector (Spain) was used as a spatial laboratory for the experimentation.

\subsection{Linking academia and transport practice: the use of bottom-up approaches}

While the transport policy-making process in Andalusia has been traditionally carried out by transport engineers, this research has used a bottom-up approach that has involved a wider range of professional domains (traffic engineers, sociologists, geographers, urban planners, economists, etc).

This has resulted in the creation of a more democratic way of establishing policy pathways, rather than the traditional deliberative process involving a narrow group of actors. The difficulty here is to determine whether participants with different backgrounds are really prepared for sharing knowledge with each other. Converting individual knowledge to collective knowledge requires interaction between "tacit" and "explicit" knowledge in an iterative fashion (Te Brömmelstroet and Bertolini, 2008). While "explicit knowledge" is characterised as easily codified and expressed in words and numbers, "tacit knowledge" is deeply rooted in personal experience in a specific context. It is harder to share. Specific attention should be paid to this phenomenon. For example, the mediator should translate into a "common language" those particular views firmly rooted in the professional experience of participants (e.g. transport planners tend to use quantitative information, while land-use planners tend to use more qualitative information). The role of the mediator was central to the translation of participants' views into a "common language" so that the focus-group workshops (see Sections 4.2 and 4.3) worked effectively. For both policy pathways lower carbon emissions and technological innovation, the mediator had to create a specific communication framework to integrate the different types of languages in order to facilitate better understanding between participants.

The creation of open dialogue spaces, where a wide range of participants interacted, was considered essential by participants to link academia and transport practice. In their opinion, this has facilitated the co-production of policies pathways with practitioners and policy-makers, confronting the more technocratic thinking on policy implementation with a more business-oriented model. However, participants also agreed that the important barriers to the effective implementation of the dynamic participation processes are mainly institutional, and related to politicians and the Andalusian planning process. Participants underlined the observation that policy-makers will have difficulties to explain the benefits of the participation process to politicians. This is due in part to the bottom-up approach, as Andalusian politicians feel safer when transport planning processes are more focused on top-down approaches where technocratic views are predominant. Furthermore, the participation process was seen as being a time-consuming process. The conclusion reached by the participants was that the dynamic participation process presented in this paper is not likely to be usable in Andalusia in the near future. Legal barriers and the low commitment of Andalusian politicians to participation processes are seen as obstacles to be overcome in real practice. Nevertheless, it was recognised by participants that the approach has added value for the Andalusian transport policy-making process. Further research could be focused on distilling this participatory framework to overcome current implementability barriers. In this respect, the present research should be seen as an initial point of innovation that needed to be refined.

\subsection{Dynamic dialogue spaces and pathways refinement}

The participatory approach followed a sequential process, where three individual policy pathways were systematically refined: lower carbon emissions, technological innovation and urban compactness (Fig. 4). This succession of explicit dialogue spaces has worked well in the context of Andalusia, producing a new participatory approach that contrasts with previous studies where a non-sequential design has been predominant (Hickman et al., 2011; Marchau and Van Der Heijden, 2003; Tuominen et al., 2014).

The sequential process was implemented according to different specialisation levels (from more generic to more specific). This has contributed to a wide acceptability level for the different PPs and pathways. The importance of continuity between the core participants throughout the different sequential phases was seen as an essential part of its success, as this allowed clarification of the choices made in previous steps. However, this group of participants can also induce a biased process if their discourse is dominant. An important aspect here is the role of the mediator. In this research, the mediator was strongly encouraged to have a central position in ensuring that no participant/ group took a dominant role in the discussion. To address that, the mediator was provided with rules of style (allotting equivalent speaking time to each party) and respect (giving a voice to all participants). Examples of that can be seen in Sections 4.2, 4.3, and 4.4.

The design of the dynamic participation processes needs to be customised for each particular situation, providing "unique processes". However, this can negatively affect to the usability of this approach, 
reinforcing institutional barriers. The central element should be to provide a recurrent refinement of the policy pathways, contributing to increasing their acceptability at both technical (from practitioners and policy-makers) and social levels (from the public). In this paper, the sequential process was completed through two refinement rounds based on different levels of specialisation from the participants. Alternative dynamic processes can be based on refining policy pathways according to different spatial scales (from national to local) or according to different levels of decisions (from strategic-oriented to blueprint-oriented).

\subsection{Learning dialogue spaces and pathways development}

In the context of increasing attention to communicative planning approaches (Bertolini, 2007; Curtis, 2011; Habermas, 2007; Innes and Booher, 2010), the policy packaging phase provides a tool that guides mutual learning processes between the different actors. However, twoway interactions between experts and researchers have been prioritised by previous backcasting studies (Hickman et al., 2009; Zimmermann et al., 2012). To address this, the present research has created explicit learning dialogue spaces. Several methodological aspects can be highlighted.

First, creating spaces where the participants had the opportunity to get to know each other and build relationships facilitated learning processes. Participants felt able to opine, and more attention was paid to critical comments and to collectively build consensus. The option of hearing each other and modulating the discourse accordingly increased opportunities for finding win-win solutions during the policy pathway refinement. An important consideration here is the time allocated to discussion. It is crucial to provide enough time for substantive discussion, and not only for introducing the individual participant's viewpoints. The time for the dialogue spaces was flexible (approximately $3 \mathrm{~h}$ for the first workshop and $4 \mathrm{~h}$ for each focus-group workshop). Participants felt that their views were accommodated.

Second, consensus between participants was the criterion used to establish the final PPs and pathways. The pursuit of consensus meant that participants systematically had to modulate their discourse and hear each other until agreement was reached. The mediator was ultimately the person in-charge to decide priorities and which packages are included in each policy pathway. This usually took place when consensus had been achieved by participants. However, the time of the workshops was limited, and several times the mediator had to adjudicate without consensus. In those cases, the mediator was encouraged to decide when majorities were higher than $75 \%$ of participants. In case of large disagreements (2 times during the research), the mediator extended the discussion until reach majorities between $60-75 \%$. This also meant that the duration of the workshops was extended. It is important to highlight the situation that simple majorities were exceptionally used when win-win solutions were extremely difficult to find.

\subsection{Further research}

This paper has provided an intermediate stage in a wider backcasting analysis for the Andalusian transport sector (2050). This wider study is largely focused on using participatory methods by examining two sets of issues: (i) the assessment of backcasting scenarios and collaborative learning processes in transport and climate change policy; and (ii) the means by which the implementation gap between transport research and policy action can be bridged. The next steps will assess the effectiveness of the integrated policy pathway in terms of real implementation in the context of Andalusia. The likelihood and desirability of this integrated pathway will be discussed with regional policymakers, exploring additional insights into how backcasting research can be implemented in a real situation.

The methodological improvements associated with the means by which participatory approaches can help in addressing the deep uncertainty of the policy packaging phase in transport have been covered here, both methodologically and practically. The literature confirms a low penetration rate for adaptive policy frameworks in real transport practice (e.g. using methods such as Real Options Analysis; Adaptive foresight; Adaptive Policymaking; Dynamic Adaptive Policy Pathways) (Haasnoot et al., 2013; Marchau et al., 2010). Consequently, bottom-up approaches can help to gain more insights into the main barriers associated with those adaptive policy frameworks, and most innovatively, to overcome them by testing solutions in (almost) real situations.

\section{Acknowledgements}

This paper has been developed in the following Marie Curie research project BACK-SCENE: Backcasting Scenarios as collaborative learning process: Involving stakeholders in transport climate policy. The project was funded by the European Union's Seventh Framework Programme, Marie Skłodowska-Curie actions (COFUND - Grant Agreement no. 291780) and theMinistry of Economy, Innovation, Science and Employment of the Junta de Andalucía (Spain).

\section{References}

Agencia Andaluza de la Energia, 2014. World energy Outlook 2014. OECD/IEA, Paris, (Available at)〈https://www.agenciaandaluzadelaenergia.es/〉.

Ashina, S., Fujino, J., Masui, T., Ehara, T., Hibino, G., 2012. A roadmap towards a lowcarbon society in Japan using backcasting methodology: feasible pathways for achieving an 80\% reduction in CO 2 emissions by 2050. Energy Policy 41, 584-598.

Banister, D., Hickman, R., 2013. Transport futures: thinking the unthinkable. Transp. Policy 29, 283-293.

Banister, D., Dreborg, K., Hedberg, L., Hunhammar, S., Steen, P., Akerman, J., 2000. Transport policy scenarios for the EU: 2020 images of the future. Innov.: Eur. J. Social. Sci. Res. 13 (1), 27-45.

Bertolini, L., 2007. Evolutionary urban transportation planning: an exploration. Environ. Plan. A 39 (8), 1998-2019.

Curtis, C., 2011. Integrating land use with public transport: the use of a discursive accessibility tool to inform metropolitan spatial planning in Perth. Transp. Rev. 31 (2), 179-197.

Haasnoot, M., Kwakkel, J.H., Walker, W.E., ter Maat, J., 2013. Dynamic adaptive policy pathways: a method for crafting robust decisions for a deeply uncertain world. Glob. Environ. Change 23 (2), 485-498.

Habermas, J., 2007. Classical pragmatism and communicative action. In: Hickman, L.A. (Ed.), Pragmatism as post-postmodernism: Lessons from John Dewey 2007. Fordham Univ Press, 21.

Hickman, R., Banister, D., 2007. Looking over the horizon: transport and reduced CO 2 emissions in the UK by 2030. Transp. Policy 14 (5), 377-387.

Hickman, R., Banister, D., 2014. Transport, Climate Change and the City. Routledge.

Hickman, R., Ashiru, O., Banister, D., 2009. Achieving carbon-efficient transportation: backcasting from London. Transp. Res. Rec.: J. Transp. Res. Board 2139, 172-182.

Hickman, R., Ashiru, O., Banister, D., 2011. Transitions to low carbon transport futures: strategic conversations from London and Delhi. J. Transp. Geogr. 19 (6), 1553-1562.

Hickman, R., Saxena, S., Banister, D., Ashiru, O., 2012. Examining transport futures with scenario analysis and MCA. Transp. Res. A: Policy Pract. 46 (3), 560-575.

Höjer, M., Mattsson, L.G., 2000. Determinism and backcasting in future studies. Futures 32 (7), 613-634.

Innes, J.E., Booher, D.E., 2010. Planning with Complexity: an Introduction to Collaborative Rationality for Public Policy. Routledge, London.

Marchau, V.A., Walker, W.E., Van Wee, G.P., 2010. Dynamic adaptive transport policies for handling deep uncertainty. Technol. Forecast. Social. Change 77 (6), 940-950.

Marchau, V.A.W.J., Van Der Heijden, R.E.C.M., 2003. Innovative methodologies for exploring the future of automated vehicle guidance. J. Forecast. 22 (2-3), 257-276.

Markus, R., Jonsson, R.D., 2006. Assessment of transport policies toward future emission targets: a backcasting approach for Stockholm 2030. J. Environ. Assess. Policy Manag. 8 (04), 451-478.

Mattila, T., Antikainen, R., 2011. Backcasting sustainable freight transport systems for Europe in 2050. Energy Policy 39 (3), 1241-1248.

Niemeier, D., Gould, G., Karner, A., Hixson, M., Bachmann, B., Okma, C., Del Valle, D.H., 2008. Rethinking downstream regulation: california's opportunity to engage households in reducing greenhouse gases. Energy Policy 36 (9), 3436-3447.

Olsson, L., Hjalmarsson, L., Wikström, M., Larsson, M., 2015. Bridging the implementation gap: combining backcasting and policy analysis to study renewable energy in urban road transport. Transp. Policy 37, 72-82.

Schade, B., Schade, W., 2005. Evaluating economic feasibility and technical progress of environmentally sustainable transport scenarios by a backcasting approach with ESCOT. Transp. Rev. 25 (6), 647-668.

Shiftan, Y., Kaplan, S., Hakkert, S., 2003. Scenario building as a tool for planning a 
sustainable transportation system. Transp. Res. D. Transp. Environ. 8 (5), 323-342.

Soria-Lara, J.A., Banister, D., 2017. Participatory visioning in transport backcasting studies: methodological lessons from Andalusia (Spain). J. Transp. Geogr. 58 $113-126$.

Te Brömmelstroet, M., Bertolini, L., 2008. Developing land use and transport PSS: meaningful information through a dialogue between modelers and planners. Transp. Policy 15 (4), 251-259.

Tuominen, A., Tapio, P., Varho, V., Järvi, T., Banister, D., 2014. Pluralistic backcasting: integrating multiple visions with policy packages for transport climate policy.
Futures 60, 41-58

Vergragt, P.J., Quist, J., 2011. Backcasting for sustainability: introduction to the special issue. Technol. Forecast. Social. Change 78 (5), 747-755.

Winyuchakrit, P., Limmeechokchai, B., Matsuoka, Y., Gomi, K., Kainuma, M., Fujino, J., Suda, M., 2011. Thailand's low-carbon scenario 2030: analyses of demand side CO 2 mitigation options. Energy Sustain. Dev. 15 (4), 460-466.

Zimmermann, M., Darkow, I.L., Heiko, A., 2013. Integrating Delphi and participatory backcasting in pursuit of trustworthiness-the case of electric mobility in Germany. Technol. Forecast. Social. Change 79 (9), 1605-1621. 